\title{
Bilateral paracoccidioidomycotic iliopsoas abscess associated with ileo-colonic lesion
}

\author{
Helena Duani ${ }^{[1]}$, Vinícius Rodrigues Taranto Nunes ${ }^{[2]}$, Anísio Borges Assumpção ${ }^{[2]}$, \\ Isadora Sofia Borges Saraiva ${ }^{[1]}$, Rodrigo Macedo Rosa ${ }^{[2]}$, Augusto Motta Neiva ${ }^{[2]}$ \\ and Ênio Roberto Pietra Pedroso[1]
}

[1]. Setor de Infectologia, Hospital das Clinicas, Universidade Federal de Minas Gerais, Belo Horizonte, MG. [2]. Instituto Alfa de Gastroenterologia, Hospital das Clinicas, Universidade Federal de Minas Gerais, Belo Horizonte, MG

\section{ABSTRACT}

This case report shows the clinical development of a patient with systemic paracoccidioidomycosis presenting with lymphatic-intestinal manifestation. The patient initially had a substantial clinical improvement but had a recrudescence after six months of sulfamethoxazoletrimethoprim oral treatment, with the emergence of feverish syndrome, lumbar pain, and intermittent claudication, characterizing a bilateral iliopsoas muscle abscess, necessitating clinicosurgical therapeutics.

Keywords: Paracoccidioidomycosis. Psoas abscess. Paracoccidioides brasiliensis.

\section{INTRODUCTION}

Paracoccidioidomycosis (PCM) is a systemic mycosis endemic in Latin America, whose agent is the dimorphic fungus Paracoccidioides brasiliensis, which manifests itself in a chronic presentation in over $90 \%$ of the cases. Its prevalence is greater among males from 30 to 60 years old, and lungs are the most frequent compromised organs. Its acute/subacute form with generalized lesions involves multiple organs and is rare and severe ${ }^{1,2}$.

We herein present a case of disseminated PCM, with involvement of lymphatic and gastrointestinal systems, and a subsequent development of bilateral iliopsoas muscle abscess (IPA), which constitutes a rare complication of the disease.

\section{CASE REPORT}

A 24-year-old rural man presenting fever, asthenia, weight loss (20kg in the period), dull abdominal pain, diarrhea and hematochezia for six months. After four months of the initial symptoms, he developed disseminated subcutaneous nodules, which began draining a purulent secretion when he was admitted to our hospital.

On physical examination, we found bilateral cervical, inguinal, and axillary lymphadenomegaly and a painful abdomen at superficial palpation, especially in the right iliac fossa.

The laboratory tests revealed a hemoglobin level of $8.9 \mathrm{~g} / \mathrm{dL}$; total leukocyte count of $6,000 / \mathrm{mm}^{3}$ (eosinophil count of $60 / \mathrm{mm}^{3}$ ); C-reactive protein of $188 \mathrm{mg} / \mathrm{dL}$; viral serology negative for HIV and hepatitis B and C; nonreactive Venereal Disease Research Laboratory (VDRL) test; negative sputum alcohol acid-resistant bacilli (AARB) test in three samples (Auramine and Ziehl Neelsen); negative sputum

Address to: Dr. Vinicius Rodrigues Taranto Nunes. Rua São Tomé do Príncipe 130, Jardim Atlântico, 31550-210 Belo Horizonte, MG, Brasil.

Fax: 5531 3492-1054

e-mail: vivas1912@pop.com.br

Received in 02/10/2011

Accepted in 14/12/2011 fungal smear; normal renal and hepatic function panels; and negative microbiological stool tests. An abdominal and pelvic computed tomography (CT) demonstrated mesenteric lymphadenomegaly, with a hypodense center. Colonoscopy evidenced multiple deep ulcers with changeable sizes and forms along the whole colon, intercalated by normal mucosa, and a deformed ileocecal valve, which favored the diagnosis of infectious ulcerative pancolitis (Figure 1). Anatomopathological examination of the colonic mucosa revealed some areas of erosion covered in fibrino-leukocytic exudate, inflammatory infiltrate in corion, with some multinucleated giant cells, and lots of round shaped yeast, in various sizes, compatible with ileum-colonic PCM (Figure 2). A biopsy of a cervical lymph node also was performed, and in the anatomopathological examination, we found the Paracoccidioides brasiliensis, with non-caseating granulomas containing multinucleated giant cells and epithelioid histiocytes, presenting a steering wheel shape, compatible with PCM granulomatous lymphadenitis.

During hospitalization, the patient was treated with venous sulfamethoxazole-trimethoprim (SMX-TMP) and amphotericin B (amphoB) deoxycholate, receiving a cumulative dose of 1,900mg after

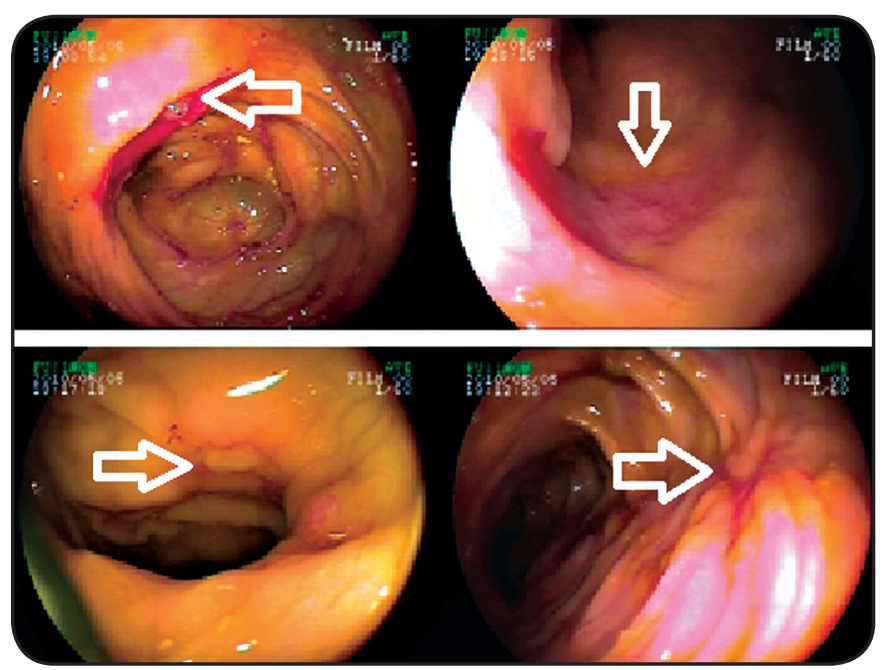

FIGURE 1 - Colonoscopy revealing the cecum and the ileocecal valve, a large ulcer, and an ulcer with fibrin (arrows). 


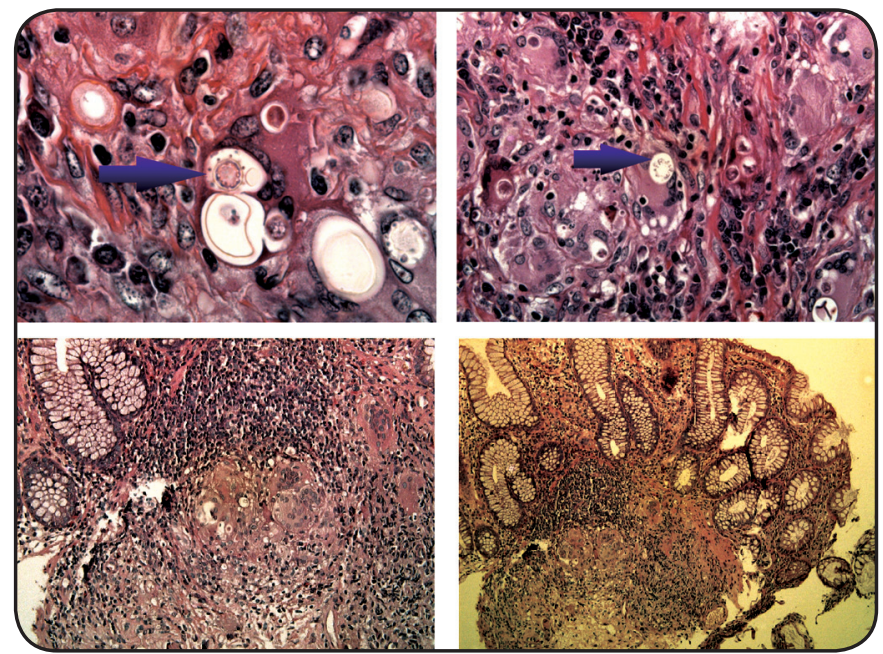

FIGURE 2 - Anatomopathological exam: fragments of colonic and ileal mucosa demonstrating areas of erosion covered in fibrino-leukocytic exudate, inflammatory infiltrate in corion, with some multinucleated giant cells and many round-shaped yeast (compatible with Paracoccidioides brasiliensis) in various sizes (arrows), compatible with ileum-colonic paracoccidioidomycosis.

38 days. A complete regression of lymphadenopathy occurred, the patient gained weight, and the diarrhea ceased. After 40 days from admission, he was discharged, with a prescription of a daily use of SMX-TMP $800+160 \mathrm{mg}$.

The patient returned 40 days later, presenting recrudescence of the initial symptoms, including pain in the left hip, limited extension of the homolateral hip, limping, and fever. Furthermore, cultures were obtained, and an anatomopathological examination of an inguinal lymph node biopsied revealed Paracoccidioides brasiliensis. He was rehospitalized and treated with amphoB plus oral itraconazole and sulphadiazine.

Abdominal and pelvic CT showed mesenteric lymphadenomegaly, enlargement of the left iliac and psoas muscles, with inner voluminous liquefaction, which extended from the level of the third lumbar vertebra ( $\mathrm{L} 3$ ) to the pelvis. Moreover, a smaller collection was observed in the right psoas muscle at L3 level, and left pyelocaliceal dilation was present (Figure 3).

An ultrasound (US)-guided lumbar percutaneous puncture of the collection was performed at L3 level, and a Cystofix $12 \mathrm{Fr}$ drain was placed inside it. There was immediate drainage of $100 \mathrm{ml}$ of thick purulent secretion, which revealed the presence of Paracoccidioides brasiliensis. Bacterial and fungal cultures of this specimen was negative.

The patient kept the initial symptomatology after eight days of drainage, being therefore submitted to a new CT scan, that demonstrated reduction of the left psoas abscess, but another collection was found involving the homolateral iliac muscle. He was then submitted to an US-guided inguinal puncture of this abscess, using $14 \mathrm{G}$ Jelco, with immediate drainage of $50 \mathrm{ml}$ of purulent secretion. The lumbar drain was left in place for 18 days.

Control CT scan 20 days after drainage showed minimal residual bilateral iliopsoas collection, and the pyelocaliceal dilation was no longer observed. After having received a cumulative dose of $2.9 \mathrm{~g}$ of amphoB and 60 days of oral itraconazole and sulfadiazine, he was discharged.

Ambulatory follow-up six months after treatment showed no signs of relapse, maintaining oral itraconazole and SMX-TMP usage.

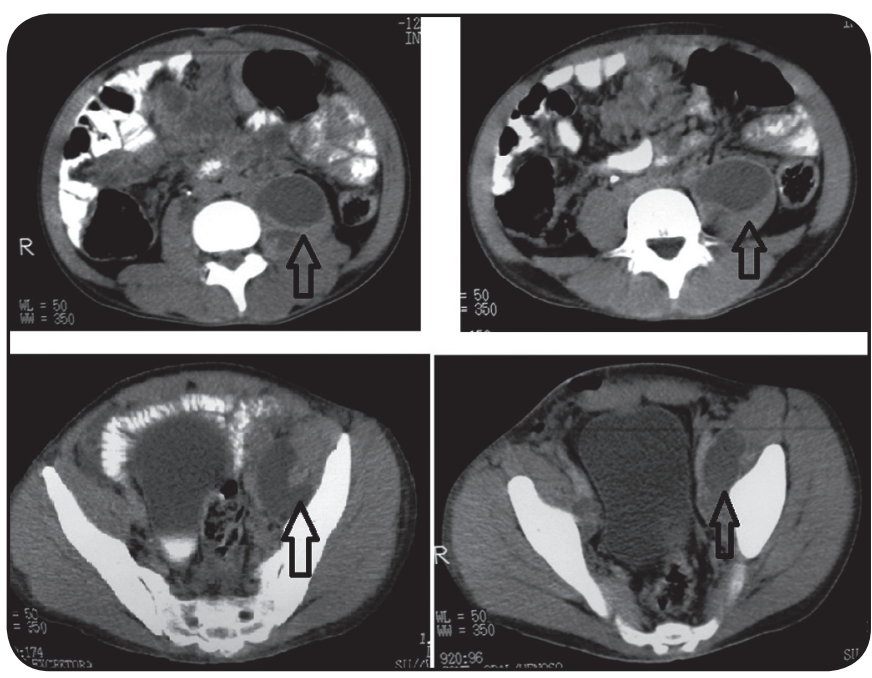

FIGURE 3 - Abdominal and pelvic computed tomography scan: mesenteric lymphadenomegaly, enlargement of the left iliac and psoas muscles, with inner voluminous liquefaction, which extended from the level of the third lumbar vertebra (L3) to the pelvis (arrows).

\section{DISCUSSION}

Paracoccidioidomycosis can manifest itself in two distinct clinical forms: acute/subacute or chronic. The acute/subacute form represents 3 to $5 \%$ of PCM cases, being more common in the first three decades of life, especially in children ${ }^{3}$. It evolves rapidly, with significant general state impairment, fever, hepatosplenomegaly, lymphadenomegaly, together with digestive, osteoarticular, and cutaneous manifestation. Mesenteric lymph node hypertrophy can lead to bowel obstruction or choledochal compression. Moreover, it can impair oral drugs and nutrient absorption, aggravating the nutritional state of the patient.

This report evidences PCM evolvement in an immunocompetent young adult presenting a subacute severe disseminated form, with colitis and systemic lymphadenomegaly, especially in the retroperitoneum, which fistulized not only to the skin but also to the lumbar musculature. The maintenance of the Paracoccidioides brasiliensis foci was strictly related to the relapse of a severe form of PCM, requiring prolonged clinicosurgical therapeutics to control the infection.

The therapeutic choice depends on the severity of the PCM, and the options are sulfas, azolics, and amphoB. The great efficacy of the sulfa and azolic drugs justifies the restricted use of amphoB, which is more toxic and is exclusively parenteral. AmphoB is reserved for more severe and systemic forms, which compromise structures beside the lungs, mucosa, and skin, and when there is imminent risk of death. Only a few studies have been held in order to define its optimal treatment. Only two randomized trials have been published so far, neither of which have collected sufficient data to assess response or cure rates 4,5 . The duration of treatment is still a matter of debate, since no randomized trials have compared different treatment durations, and are based mainly on data from open studies and specialist opinions ${ }^{6}$. In this report, the patient had initially been treated with venous SMX-TMP and amphoB because of the severity of the manifestations, and there was a great initial response. After being discharged, a prolonged oral SMX-TMP therapy proceeded, with a 
good compliance. However, at this stage of treatment, the disease relapsed, manifesting as cold retroperitoneal abscesses. Therapeutics at that moment was based on antifungal association because of the disease severity and life threatness.

The iliopsoas muscle abscess (IPA) is a retroperitoneal collection in the space defined by the iliac and psoas muscles, usually determined by a bacterial infection. It is considered a rare medical entity; nonetheless, with the advent of CT scan for evaluation of patients with sepsis with undetermined focus, the diagnosis of IPA has become more frequent. Its emergence is related to two mechanisms: primary, with hematogenic spread, and secondary, when related to adjacent structures infection.

The diagnosis, evolution and treatment of IPA are well described for bacterial infection. Iliopsoas abscess related to PCM is even more rare and there is little information about this PCM entity ${ }^{7}$. In the patient reported, the most likely mechanism of IPA formation was the fistulization of retroperitoneal lymph nodes into the iliopsoas muscle compartment, simultaneous to cutaneous fistulization of the superficial lymph nodes.

The classical triad symptoms, characterized by fever, lumbar pain, and claudication, are present in only $30 \%$ of the cases ${ }^{8}$. Other symptoms include inguinal bulge, malaise, anorexia, and weight loss. In $60 \%$ of the cases, the US confirms the diagnosis, with the CT scan considered the gold standard for diagnosis.

Historically, the initial IPA treatment was based on extraperitoneal surgical drainage, associated with adequate antimicrobial therapy. The first IPA radiologic (US, CT) guided percutaneous drainage occurred in $1984^{\circ}$, and since then, the best therapeutic option has been on debate. So far, the treatment choice is the guided percutaneous drainage, as it is the least invasive and associated with lower morbidity and mortality ${ }^{10}$; however, many local and systemic factors of each patient may influence the therapeutic choice ${ }^{11}$.

After the first drainage, there was only partial improvement in the patient reported, requiring the repetition of the CT scan, which showed that the left IPA was composed of two distinct compartments, requiring a new US-guided percutaneous puncture. Therapeutic failure after percutaneous drainage is rare, as described by Castademir et al, who revealed that this method was efficacious in 21 of 22 patients; nonetheless, when it happens, surgical treatment is indicated ${ }^{12}$. The right IPA was of little volume, and we opted to treat it with antibiotics only, a plausible treatment for small abscesses.

The main complications of IPA are deep venous thrombosis, bowel obstruction, ureteral obstruction, and sepsis. In this case, pyelocaliceal dilation was due to extrinsic compression and was fully reverted after drainage, with no renal sequela.

Paracoccidioidomycosis reveals itself as a variable clinical entity that ought to be remembered in the clinical diagnosis of a localized or systemic disease, with possible involvement of the lungs, skin, mucosa, central nervous system, retroperitoneal musculature or lymph nodes, intestine, adrenal, kidneys, or prostate and likely association with tuberculosis, neoplasms, and sepsis. In this report, we presented a patient with multiple organ compromise because of disseminated PCM, apparently with antifungal resistance, necessitating broadspectrum antibiotics and radiologic-guided percutaneous drainage of cold retroperitoneal abscesses, who evolved with slow recovery despite all therapeutics. Although the first description of PCM goes back over 100 years, its optimal treatment is not yet well-defined. The lack of information about diagnosis and treatment may contribute to the development of unusual forms of presentation that are capable of producing significant damage and death.

\section{ABSTRACT IN PORTUGUESE}

\section{Abscesso paracoccidioidomicótico bilateral do iliopsoas associado ao acometimento íleo-colônico}

Este relato de caso descreve a evolução clínica de paciente com paracoccidioi-domicose sistêmica com manifestação linfática-intestinal. O paciente evoluiu inicialmente com melhora clínica acentuada e recrudescência após seis meses de uso de SMX-TMP pela via oral, com o surgimento de síndrome febril, dor lombar, e claudicação intermitente, caracterizando um abscesso bilateral do músculo íleopsoas, com necessidade de terapêutica clínico-cirúrgica.

Palavras-chaves: Paracoccidioidomicose. Abscesso do psoas. Paracoccidioides brasiliensis.

\section{REFERENCES}

1. Coutinho ZF, Silva D, Lazera M, Petri V, Oliveira RM, Sabroza PC, et al. Paracoccidioidomycosis mortality in Brazil (1980-1995). Cad Saude Publica 2002; 18:1441-1454.

2. Shikanai-Yasuda MA, Queiroz-Telles F, Mendes RP, Colombo AL, Moretti ML. Guidelines in Paracoccidioidomycosis. Rev Soc Bras Med Trop 2006; 39:297-310.

3. Pereira RM, Bucaretchi F, Barison EM, Barison Ede M, Hessel G, Tresoldi AT. Paracoccidioidomycosis in children: clinical presentation, follow-up and outcome. Rev Inst Med Trop Sao Paulo 2004; 46:127-131.

4. Shikanai-Yasuda MA, Benard G, Higaki Y, Del Negro GM, Hoo S, Vaccari EH, et al. Randomized trial with itraconazole, ketoconazole and sulfadiazine in paracoccidioidomycosis. Med Mycol 2002; 40:411-417.

5. Queiroz-Telles F, Goldani LZ, Schlamm HT, Goodrich JM, Espinel-Ingroff A, ShikanaiYasuda MA. An open-label comparative pilot study of oral voriconazole and itraconazole for long-term treatment of paracoccidioidomycosis. Clin Infect Dis 2007; 45:1462-1469.

6. Shikanai-Yasuda MA. Pharmacological management of paracoccidioidomycosis. Expert Opin Pharmacother 2005; 6:385-397.

7. Neves MT, Livani B, Belangero WD, Tresoldi AT, Pereira RM. Psoas Abscesses Caused by Paracoccidioides brasiliensis in na Adolescent. Mycopathologia 2009; 167:89-93.

8. Mallick IH, Thoufeeq MH, Rajendran TP. Ileopsoas Abscess. Postgrad Med J 2004; 80:459-462.

9. Mueller PR, Ferrucci Jr JT, Wittenberg J, Simeone JF, Butch RJ. Iliopsoas Abscess: Treatment by CT-guided Percutaneous Catheter Drainage. AJR Am J Roentgenol 1984; 142:359-362.

10. Gupta S, Suri S, Gulati M, Singh P. Ilio-psoas abscesses: Percutaneous Drainage Under Image Guidance. Clin Radiol 1997; 52:704-707.

11. Yacoub WN, Sohn HJ, Chan S, Petrosyan M, Vermaire HM, Kelso RL, et al. Psoas Abscess Rarely Requires Surgical Intervention. Am J Surg 2008; 196:223-227.

12. Cantasdemir M, Kara B, Cebi D, Selcuk ND, Numan F. Computed Tomography-guided Percutaneous Catheter Drainage of Primary and Secondary Iliopsoas Abscesses. Clin Radiol 2003; 58:811-815. 